\title{
1 Impact of excavation damage on the thermo-hydro-mechanical \\ 2 properties of natural Boom Clay
}

3 Linh-Quyen DAO ${ }^{1}$, Yu-Jun CUI ${ }^{1}$, Anh-Minh TANG ${ }^{1}$, Jean-Michel PEREIRA ${ }^{1}$, Xiang-Ling LI ${ }^{2}$, Xavier

4 SILLEN $^{3}$

$5 \quad{ }^{1}$ Ecole des Ponts ParisTech, Navier/CERMES, Marne la Vallée, France

$6{ }^{2}$ European Underground Research Infrastructure for Disposal of nuclear waste In Clay Environment, ESV EURIDICE GIE, Mol,

7 Belgium

$8 \quad{ }^{3}$ Belgian Agency for Radioactive Waste and Enriched Fissile Materials (ONDRAF/NIRAS), Brussels, Belgium

19 Corresponding author:

20 Prof. Yu-Jun CUI

21 Ecole des Ponts ParisTech

22 6-8 av. Blaise Pascal, Cité Descartes, Champs-sur-Marne

2377455 Marne-la-Vallée cedex 2

24 France

26 Email: yujun.cui@enpc.fr

27 Phone: +33164153550

28 Fax: +33164153562 
Abstract

31 Boom Clay has been considered as a potential host-rock for the geological radioactive waste disposal in

32 Belgium. In this context, it is important to well understand its thermo-hydro-mechanical behaviour around

33 the disposal galleries. In this study, the effect of excavation damage on the thermo-hydro-mechanical

34 properties of natural Boom Clay around the Connecting gallery (excavated in 2002) in the Mol

35 underground Research Laboratory HADES (High-Activity Disposal Experimental Site) was investigated.

36 Several samples taken from a horizontal borehole drilled in July 2012 were tested. The thermal

37 conductivity in three different orientations (perpendicular, parallel, and $45^{\circ}$ to the bedding plane) were

38 measured using the needle probe method. The results show a cross-anisotropy of natural Boom Clay and

39 an impact of the excavation damage on the thermal property of samples near the gallery. To further

40 investigate the anisotropy behaviour, bender element tests were carried out under unconfined conditions

41 to determine the small-strain shear modulus also in three different orientations. The obtained results

42 confirm the anisotropic behaviour of Boom Clay. Moreover, the evolution of small-strain modulus with the

43 distance from the gallery axis $(r)$ was found to be similar to that of thermal conductivity: the values in the

44 zone near the gallery are lower than those in the far field. From these experimental data, an extent of the

45 excavation damaged zone (EDZ) of $4 \mathrm{~m}$ from the connecting gallery axis was determined. Further

46 investigations on the microstructure of several samples taken at different distances $r$ by mercury intrusion

47 porosimetry (MIP) and scanning electron microscope (SEM) methods were carried out. Macro-pores of

48 diameter $\geq 5 \mu \mathrm{m}$ were identified in the samples near the gallery. The identified macro-pores were related

49 to the effect of excavation damage, and a damage variable was thus defined, allowing a damage model to

50 be developed. The values of the two model parameters have been determined from the observed

51 relationship between macro-porosity and thermal conductivity. Comparisons between predicted and

52 experimental results in terms of small strain shear modulus and hydraulic conductivity have shown

53 reasonable agreement.

54 Keywords: Boom Clay; excavation damage; thermal conductivity, shear modulus, microstructure;

55 anisotropy 


\section{Introduction}

66 Geological formation of stiff clays or Claystone is often considered as potential host formation for the radioactive waste disposal at great depth. In Europe, several Underground Research Laboratories (URLs) have been constructed in stiff clay/Claystone formations such as the HADES URL (Belgium) in Boom Clay, Mont Terri URL (Switzerland) in Opalinus Clay, Bure URL (France) in Callovo-Oxfordian Claystone, etc. In this context, the damaged or disturbed zone around the gallery due to excavation is one of the most important research issues. This zone has several names and definitions depending on the research programs (Lanyon, 2011). According to Tsang and Bernier (2004), Tsang et al. (2005), Bastiaens et al. (2007), and Lanyon (2011), this zone is defined as the excavation damaged zone (EDZ) where the hydromechanical and geochemical modifications induced by the excavation lead to significant changes in flow and transport properties. For instance, these changes can be characterised by an increase of several magnitudes in hydraulic conductivity.

The characterisation of EDZ was investigated experimentally for several host formations such as Boom Clay (Mertens et al., 2004), Callovo-Oxfordian Claystone (Armand et al., 2007), Opalinus Clay (Popp et al., 2008). Depending on the host formation properties, time and budget, the characterisation method can be different (Lanyon, 2011). In order to investigate the fractures/damage induced by excavation and the lithology changes, borehole core drilling and logging are often used. The extent of EDZ can be identified by the changes in matrix geophysical and hydromechanical properties that are determined by the tests on the borehole cores. For instance, Matray et al. (2007) determined the EDZ extent in Tournemire's argillite (France) through changes in degree of saturation; Autio et al. (1998) did that in Äspö Hard Rock (Sweden) through changes in porosity.

During the excavation of Connecting Gallery (diameter $4.8 \mathrm{~m}$ ) in HADES URL, fractures were intensively investigated. (Bastiaens et al., 2003; Mertens et al., 2004). The fracture pattern consists of two conjugated curved planes and the extent of the fractured zone in the horizontal direction is larger than that in the vertical one. Two cored borings, one horizontal and one vertical, were performed shortly after the construction of the Connecting gallery to assess the radial extent of the fractures. Fractures presumably related to the excavation were found up to about 1 metre in the horizontal core and up to about $0.6 \mathrm{~m}$ in the vertical core (Bernier et al., 2006). Charlier et al. (2010) analysed the extent of plastic zone developed around the gallery of PRACLAY (diameter $2.5 \mathrm{~m}$ ) at the end of excavation through numerical simulations in 2D, axisymmetric and 3D conditions, and the obtained results are in good agreement with the field observation: depending on the values adopted for the parameters of the constitutive model, the calculated plastic zone can extend up to about $3 \mathrm{~m}$ in the vertical direction and about $10 \mathrm{~m}$ in the horizontal direction when considering material anisotropy. 
the extent of EDZ. These two boreholes have a distance of $3.6 \mathrm{~m}$ from each other. The velocity of compression wave $V_{\mathrm{P}}$ was measured using a mini-sonic probe. Significant data scatter was observed in the zone up to about $2 \mathrm{~m}$ from the gallery extrados, i.e. the outer surface of the gallery's wall ( $2.8 \mathrm{~m}$ in $2000-4$ and $1 \mathrm{~m}$ in 2000-5), suggesting significant damage of this zone.

Another in-situ measure allowing the characterisation of the EDZ around the Connecting gallery is the hydraulic conductivity $(k)$. Yu et al. (2011a) reported a large investigation over 30 years on the hydraulic conductivity of Boom Clay. Some data involve the evolution of hydraulic conductivity with the distance from the gallery extrados. For instance, two piezometers equipped with pressure controller and highdefinition balance were installed: R55D (vertical) and R55E (horizontal). The measurement obtained from the vertical piezometer is mainly the contribution of $k_{\mathrm{h}}$ or $k_{/ /}$(hydraulic conductivity parallel to the bedding plane), while the measurement obtained from the horizontal piezometer $\left(k_{\mathrm{g}}\right)$ is the combined contribution of $k_{\perp}$ (hydraulic conductivity perpendicular to the bedding plane) and $k_{/ /}(Y u$ et al., 2013a). The relation between $k_{\mathrm{g}}, k_{\perp}$ and $k_{/ /}$after Roy (1991) is:

$$
k_{g}=\sqrt{k_{\perp} \cdot k_{/ /}}
$$

Using Eq. (1), the vertical hydraulic conductivity can be deduced using the measurements from the vertical and horizontal piezometers. The obtained results show that the hydraulic conductivity is strongly disturbed in the zone of $6 \mathrm{~m}$ from the gallery's wall. This extent is larger than that deduced from $V_{\mathrm{p}}$ measurements 116 (2 $\mathrm{m}$ from the gallery's wall).

Several studies showed that the EDZ in Boom Clay can be sealed after a certain time, with a hydraulic behaviour that becomes close to that of intact Boom Clay (Bastiaens et al., 2007; Mertens et al., 2002). On the other hand, healing, i.e. restoration of original mechanical properties, has not been demonstrated. This aspect was investigated in this study by testing Boom Clay cores taken 10 years after the gallery excavation (2002). The EDZ extent was appreciated based on changes in small-strain shear modulus $\left(G_{0}\right)$ and thermal conductivity $(\lambda)$. Different directions with respect to the bedding plane were considered, allowing the anisotropic behaviour to be studied. Furthermore, microstructure changes were also analysed, allowing identification of the creation of a population of macro-pores that was due to the excavation damage. A parameter related to these macro-pores was then defined, allowing description of the effect of excavation damage on the thermo-hydro-mechanical properties (i.e. thermal conductivity - $\lambda$, small-strain shear modulus - $G_{0}$ and hydraulic conductivity - $k$ ) of Boom Clay.

\section{Materials and methods}

\subsection{Materials}

131 Boom Clay is located in the North of Belgium at depth between $185 \mathrm{~m}$ and $287 \mathrm{~m}$ at Mol (Mertens et al., 132 2004). Its bedding plane is considered to be almost horizontal; its layer is gently dipping $\left( \pm 1^{\circ}\right)$ toward the 133 North-North-East (Mertens et al. 2003). This material mainly consists of clay minerals dominated by 
kaolinite and illite (Lima, 2011, Dehandschutter et al., 2005). In this study, several samples were taken from a horizontal borehole (R66-67) of $100 \mathrm{~mm}$ diameter (the axis is parallel to the bedding plane). This borehole was drilled in July 2012 from the connecting gallery which was excavated in 2002 with $4.0 \mathrm{~m}$ diameter and $0.4 \mathrm{~m}$ thick liner. The full code of the borehole or cores is: Boom Clay / Mol Site / HADES borehole 2012-2 / Connecting gallery / Ring 66-67W / $0.40 \mathrm{~m}$ to $20.3 \mathrm{~m}$ from the intrados of the lining. After being extracted, each core sample was vacuum-packaged in aluminium foil to minimise water loss by evaporation.

141 The initial suction of Boom Clay after opening these aluminium foils was measured using a dew-point 142 hygrometer and a value of about $3 \mathrm{MPa}$ was obtained which is close to that estimated by Delage et al. 143 (2007). Other parameters such as water content $(w)$, degree of saturation $\left(S_{r}\right)$ were also measured. 144 Further examination shows that the relationship between suction and water content was in good 145 agreement with the retention curve reported by Delage et al. (2007).

\subsection{Thermal conductivity measurement}

148 After trimming from core, the samples (100 mm in diameter and $60 \mathrm{~mm}-90 \mathrm{~mm}$ in height) were then 149 slightly confined by means of an adhesive tape so as to avoid further crack propagation and any 150 perturbation. The thermal conductivities of natural Boom Clay in three orientations (parallel, perpendicular 151 and $45^{\circ}$ to the bedding plane) were measured using a thermal needle probe - KD2 Pro. A single needle 152 (60 $\mathrm{mm}$ in length, $1.3 \mathrm{~mm}$ in diameter) was inserted into the soil specimen (Figure 1). In this needle probe 153 method (or line source method), the theory of axisymmetric heat diffusion from an infinite line source 154 within an infinite surrounding medium was used. Hence, a radial heat flow is produced within the 155 specimen while measuring temperature changes over time. More details can be seen in Tang et al. 156 (2008). In order to measure the thermal conductivity in three orientations, three holes were drilled in each 157 sample in order to vary the angle $\theta$ between the axis of needle probe and the bedding plane $\left(\theta=0^{\circ}, 45^{\circ}\right.$, $15890^{\circ}$ ) (see Figure 1). Note that in the case of $\theta=90^{\circ}$, the measured thermal conductivity $\lambda_{90}$ is not the value 159 in the direction perpendicular to the bedding plane $\left(\lambda_{\perp}\right)$. The true value of $\lambda_{\perp}$ is back-calculated from $\lambda_{/ /}$(or $160 \lambda_{0}$ ) and the apparent thermal conductivity $\lambda_{90}$ using Eq. (2) (Penner, 1963):

$$
\lambda_{\perp}=\frac{\left(\lambda_{90}\right)^{2}}{\lambda_{0}}
$$

161 As the samples used were at unsaturated state, Johansen's method (Farouki, 1986) for fine unfrozen soils 162 was used to calculate the thermal conductivity at saturated state $\left(\lambda_{\text {sat }}\right)$ from the thermal conductivity at 163 unsaturated state $(\lambda)$ and dry state $\left(\lambda_{\text {dry }}\right)($ Eq. (3)):

$$
\lambda_{s a t}=\frac{\left(\lambda-\lambda_{d r y}\right)}{K_{e}}+\lambda_{d r y}
$$

164 where 


$$
\begin{aligned}
& K_{e} \cong \log S_{r}+1.0 \\
& \lambda_{d r y}=\frac{0.135 \gamma_{d}+64.7}{2700-0.947 \gamma_{d}} \pm 20 \%(\mathrm{~W} / \mathrm{mK})
\end{aligned}
$$

165 where $\gamma_{d}$ is the dry density expressed in $\mathrm{kg} / \mathrm{m}^{3}$.

\subsection{Shear modulus measurement}

168 The small-strain shear modulus $\left(G_{0}\right)$ in different orientations of natural Boom Clay was determined by 169 performing bender elements tests under unconfined conditions. In a bender element test, the velocity of 170 shear wave $\left(V_{S}\right)$ is determined allowing calculation of the small-strain shear modulus $\left(G_{0}\right)$. The 171 experimental set-up used is depicted in Figure 2 (only soil sample and the transmitter are presented). The 172 receiver placed under the soil sample is not sketched in this figure.

173 For each sample (100 mm in diameter and $55 \mathrm{~mm}-80 \mathrm{~mm}$ in height), the shear wave in three different

174 orientations $\left(V_{\mathrm{hv}}, V_{\mathrm{hh}}, V_{\mathrm{h} 45}\right)$ were generated by letting vibrate the transmitter element in the direction 175 perpendicular, parallel and at $45^{\circ}$ with respect to the bedding plane. Note also that the direction of wave 176 propagation is always parallel to the bedding (see Figure 2). The travel times $(\Delta t)$ of shear wave was 177 determined. Then three small-strain shear modulus $G_{\mathrm{hv}}, G_{\mathrm{hh}}, G_{\mathrm{h} 45}$ were calculated using Eq. (6) (Zeng and $178 \mathrm{Ni}, 1999)$ :

$$
G_{0(i j)}=\rho V_{s(i j)}^{2}
$$

where $i$ and $j$ are the directions of shear wave propagation and particle vibration in the $\sigma_{i}-\sigma_{j}$ plane, respectively; $\rho$ is the total density of soil $\left(\mathrm{Mg} / \mathrm{m}^{3}\right) ; G_{0}$ is small-strain shear modulus $(\mathrm{kPa}), V_{\mathrm{s}}$ is shear wave velocity ( $\mathrm{m} / \mathrm{s})$ determined by Eq. (7):

$$
V_{S}=\frac{l}{\Delta t}
$$

where $/$ is the travel length of shear wave.

Note that the samples used for the bender element tests were the same as those used in the thermal conductivity tests. Note also that the water content in these cores slightly decreased during the conservation in the laboratory, resulting in an increase in suction. The values range from $3 \mathrm{MPa}$ (suction

186 measured during thermal conductivity tests) to $5 \mathrm{MPa}$ (suction measured during the bender element 187 tests).

\subsection{Microstructural investigations}


Two microstructural observation methods were used: scanning Electron Microscopy (SEM) and Mercury Intrusion Porosimetry (MIP). Note that the samples were freeze-dried prior to observations to minimise the modification of soil microstructure (Delage and Pellerin, 1984). The MIP tests were performed on an "AutoPore IV 9500 - Micromeritics Instrument Corp". This equipment has two stages of pressure application. In the first stage, the equipment performs mercury intrusion at low pressures in the range between 0.0035 and $0.2 \mathrm{MPa}$, and measuring apparent pore diameters between $400 \mu \mathrm{m}$ and $3 \mu \mathrm{m}$. In the second stage, the high-pressure is applied between 0.2 and $227.5 \mathrm{MPa}$, measuring pores diameters ranging from $3 \mu \mathrm{m}$ to $0.005 \mu \mathrm{m}$.

198

\section{Experimental results}

\subsection{Shear stiffness and thermal conductivity}

The variations of $G_{\mathrm{hv}}, G_{\mathrm{h} 45}, G_{\mathrm{hh}}$ with the distance $r$ from the axis of gallery for each sample are presented in Figure 3. It appears that $G_{\mathrm{hh}}$ displays a clear trend with distance $r$ : It stabilises at $1450 \mathrm{MPa}$ in the zone far from the gallery, decreases to $1200 \mathrm{MPa}$ at $r=4 \mathrm{~m}$ and then drops to $800 \mathrm{MPa}$ at $r=2.5 \mathrm{~m}$. For $G_{\mathrm{hv}}$, except two values (638 MPa at $r=2.7 \mathrm{~m}$ and $1403 \mathrm{MPa}$ at $r=3.8 \mathrm{~m}$ ), a significant decrease is identified from the far field (1200 MPa at $r=9.2 \mathrm{~m}$ ) to the near field (808 MPa at $r=2.5 \mathrm{~m}$ ). The value of $G_{\mathrm{hv}}$ at $r=$ $16 \mathrm{~m}$ is equal to the value of $G_{\mathrm{hh}}$. This is quite surprising because $G_{\mathrm{hv}}$ is expected to be lower than $G_{\mathrm{hh}}$ due to the cross-anisotropy of Boom Clay formation. For $G_{n 45}$, except two values at $r=4 \mathrm{~m}(1098 \mathrm{MPa})$ and $r=$ $16 \mathrm{~m}(1009 \mathrm{MPa})$, it seems to stabilise around $1300 \mathrm{MPa}$ at the distance $\mathrm{r}$ from $3.8 \mathrm{~m}$ to $9.2 \mathrm{~m}$, then decreases to $1066 \mathrm{MPa}$ at $r=2.5 \mathrm{~m}$. In spite of the irregular evolutions of $G_{\mathrm{hv}}$ and $G_{\mathrm{h} 45}$, it appears clearly that the shear stiffness of the zone near the gallery $r<4 \mathrm{~m}$ (about $1.6 \mathrm{~m}$ from the gallery extrados) is lower than that in the far field. It is also found that the obtained values of $G_{\mathrm{hv}}$ and $G_{\mathrm{hh}}$ in the far field are in good agreement with those obtained by Lima (2011) under unconfined condition ( $G_{\mathrm{hh}}=1483 \mathrm{MPa}$ and $G_{\mathrm{vh}}$ $=1135 \mathrm{MPa}$ ). Areias et al. (2012) also measured the shear wave velocity in the field and obtained a value of $V_{\mathrm{s}}$ around $800 \mathrm{~m} / \mathrm{s}$ that corresponds to a value of $G_{0}$ of $1280 \mathrm{MPa}$. This is in agreement with the value obtained in this study.

The results of thermal conductivity at saturated state in the directions parallel ( $\lambda_{/ /}$measured), perpendicular ( $\lambda_{\perp}$ calculated) and $45^{\circ}\left(\lambda_{45}\right.$ measured) to the bedding plane are shown in Figure 4 versus the distance $r$ from the axis of gallery. For the $\lambda_{/ /}$measured, the value stabilises at $1.6 \mathrm{~W} /(\mathrm{m} . \mathrm{K})$ in the zone far from the gallery then drops to $1.46 \mathrm{~W} /(\mathrm{m} . \mathrm{K})$ at $r=3.4 \mathrm{~m}$ and afterwards quickly decreases to 1.3 $\mathrm{W} /(\mathrm{m} . \mathrm{K})$ at $r=2.5 \mathrm{~m}$. The value of $\lambda_{/ /}$in the far field $(r>4 \mathrm{~m})$ is close to that found by Chen et al. (2011) by back analysis of a metre-scale in situ heater test $(1.65 \mathrm{~W} /(\mathrm{m} . \mathrm{K}))$. The variation trend of $\lambda_{45}$ is similar to that of $\lambda_{/ /}$: the value stabilises at $1.5 \mathrm{~W} /(\mathrm{m} . \mathrm{K})$ then quickly decreases to $1.2 \mathrm{~W} /(\mathrm{m} . \mathrm{K})$ at $r=2.5 \mathrm{~m}$. For $\lambda_{\perp}$ calculated, the variation is not as regular as for $\lambda_{/ /}$and $\lambda_{45}$ : the value in the far field varies slightly between 0.95 and $1.05 \mathrm{~W} /(\mathrm{m} . \mathrm{K})$, drops down to $0.8 \mathrm{~W} /(\mathrm{m} . \mathrm{K})$ at $r=2.7 \mathrm{~m}$ then increases to $0.9 \mathrm{~W} /(\mathrm{m} . \mathrm{K})$ at $r=2.5 \mathrm{~m}$. 
excavation damage is confirmed, even more than 10 years after the excavation, at least on thermalmechanical properties of unconfined samples.

\subsection{Microstructural investigation}

Mercury Intrusion Porosity (MIP) and Scanning Electron Microscopy (SEM) tests were carried out on several Boom Clay samples located at three distances $r(2.5 \mathrm{~m}, 2.7 \mathrm{~m}$ and $9.2 \mathrm{~m})$ to the gallery axis. The microstructural investigations were performed after measuring the thermal conductivity and the shear modulus. The bedding plane of Boom Clay can be detected at macroscopic scale as shown in Figure 5. The physical properties of Boom Clay samples used for MIP and SEM tests can be found in Table 1. Figure 6 shows the pore size distribution curves for the three samples. From pore size $5 \mathrm{~nm}$ to $5000 \mathrm{~nm}$ (i.e. $5 \mu \mathrm{m}$ ), the curves have a similar shape (Figure 6a) with a well-defined pore population at $80 \mathrm{~nm}$. This observation is consistent with that by Lima (2011) and Nguyen (2013). The curves also revealed that these samples have almost no pores in the range from $1 \mu \mathrm{m}$ and $5 \mu \mathrm{m}$. However, for the range beyond 5 $\mu \mathrm{m}$, the two samples located near the gallery's wall ( $r=2.5 \mathrm{~m}$ and $r=2.7 \mathrm{~m}$ respectively) show the presence of macro-pores, with the macro-pores being more pronounced for the sample which is closest to the gallery - $r=2.5 \mathrm{~m}$. These macro-pores could be related to the fissures created by the gallery excavation or to the excavation damage. It is also observed from Figure $6 \mathrm{~b}$ that the final value of the intruded mercury void ratio (mercury intruded volume/volume of soil particles) for the three samples are always lower than their corresponding global soil void ratio $e$ (see Table 1) due to non-intruded porosity (Lima, 2011).

To further evaluate the soil behaviour at microscopic level, the intruded mercury void ratio of macro-pore $e_{\mathrm{M}}$ is used, which is the ratio of the mercury intruded volume of macro pore $V_{\mathrm{M}}$ to the volume of soil particles $V_{s}$ (Eq. (8)):

$$
e_{M}=\frac{V_{M}}{V_{s}}
$$

The $e_{M}$ of the Boom Clay samples is estimated by using the curves $e_{M}-D$ (Figure 6b). For the three samples tested: $e_{\mathrm{M}}=0.05(r=2.5 \mathrm{~m}) ; e_{\mathrm{M}}=0.02(r=2.7 \mathrm{~m}) ; e_{\mathrm{M}}=0.01(r=9.2 \mathrm{~m})$. Figure 7 shows the evolution of $e_{\mathrm{M}}$ with distance $r$. It can be observed that the nearest sample to the gallery $(r=2.5 \mathrm{~m})$ has the maximum value of $e_{\mathrm{M}}$, and the sample at $r=9.2 \mathrm{~m}$ has the minimum.

The pore size distribution analysis was completed by the SEM observation. The views perpendicular and parallel to the bedding plane for the samples taken from three different distances, $r=2.5 \mathrm{~m}, 2.7 \mathrm{~m}$ and 9.2 $\mathrm{m}$, are shown in Figure 8, Figure 9 and Figure 10, respectively. For the sample located at $r=2.5 \mathrm{~m}$, two photographs were taken at two dimensions: $1800 \times 1400 \mu \mathrm{m}$ (Figure 8a), $1500 \times 1100 \mu \mathrm{m}$ (Figure 8b). In Figure $8 \mathrm{a}$, the beam of electron of microscope being parallel to the bedding plane, the bedding plane was clearly identified. In addition, a crack of about $50 \mu \mathrm{m}$ wide parallel to the bedding plane is detected. In Figure $8 \mathrm{~b}$, the beam of electron of microscope being perpendicular to the bedding plane, hence several 


$$
\sigma_{i j}^{*}=\frac{\sigma_{i j}}{1-D}
$$
the crack observed in Figure 9a. clearly observed. same dimension and density.

\subsection{Damage variable}

clay platelets parallel to each other are observed, without the presence of large cracks. From the pore size distribution curve at $r=2.5 \mathrm{~m}$ (Figure 6a), macro-pores are observed in the range from $10 \mu \mathrm{m}$ to $100 \mu \mathrm{m}$. The crack identified in Figure 8a corresponds to these identified macro-pores.

The SEM photographs of the second sample located at $r=2.7 \mathrm{~m}$ are presented in Figure 9. When focusing the beam of electron parallel to the bedding plane (Figure 9a), the bedding plane is still well detected. Moreover, a crack as large as $40 \mu \mathrm{m}$ and parallel to the bedding plane is also observed. In Figure $9 \mathrm{~b}$, as the dimensions picture are smaller $(850 \times 650 \mu \mathrm{m})$ that that of Figure $8 \mathrm{~b}$, clay platelets are identified more clearly: they are superimposed upon each other. For this sample, the pore size distribution curve (Figure 6a) also shows some macro-pores of $10 \mu \mathrm{m}$ to $100 \mu \mathrm{m}$. This is also in good agreement with

For the sample located far from the gallery $(r=9.2 \mathrm{~m})$, two photographs at two scales were taken: $2300 \mathrm{x}$ $1800 \mu \mathrm{m}$ (Figure 10a with the beam of electron parallel to the bedding plane) and $640 \times 500 \mu \mathrm{m}$ (Figure $10 \mathrm{~b}$ with the beam of electron perpendicular to the bedding plane). Although the dimensions of Figure 10a are close to those of Figure $6 \mathrm{a}$ and Figure $8 \mathrm{a}$, only the bedding plane is detected and no crack is found. As the dimension of Figure 10b is slightly smaller than that of Figure 9b, several bedding planes are

Summarising, there is a good agreement between the MIP and SEM analyses, suggesting that the void ratio of macro-pore $e_{\mathrm{M}}$ (diameter $\geq 5 \mu \mathrm{m}$ ) is due to excavation damage. In other words, the excavation damage zone still exists even more than 10 years after the excavation. There are certainly some desiccation cracks after the sample has been taken out of the borehole. But the others results on Boom Clay samples at the "perfect" state (far field and undamaged condition) didn't show the cracks with the

\section{Prediction of thermo-hydro-mechanical properties}

Many theories of continuous damage mechanics were developed based on the concept of effective stress of Kachanov (1958) (see (Ambroziak, 2007; Gross and Seelig, 2011). It is assumed that the relationship between the effective stress in the damaged material $\left(\sigma_{\mathrm{ij}}^{*}\right)$ and that of the undamaged material $\left(\sigma_{\mathrm{ij}}\right)$ is defined by a damage variable $D$ (Eq. (9)):

For a linear elastic material, the amount of damage can be determined by Eq. (10): 


$$
D=1-\frac{E^{*}}{E}
$$

290

291

292

293

294

295

296

297

298

299

300

301

302

303

304

305

306

307

308

309

310

311

312

313

314

315

316

317

318

where $E$ is the Young's modulus of undamaged material, $E^{*}$ is the Young modulus of damaged material.

In this study, as a decrease of thermal conductivity and small-strain shear modulus has been identified in the location near the galley and this decrease is related to the excavation damage characterised by the creation of macro-pores, a semi-empirical expression can be proposed to estimate the effect of excavation damage on the properties of Boom Clay (see Eq. (11)). In this expression, parameter $e_{M}$ defined by the pores larger than $5 \mu \mathrm{m}$ is used as a measure of damage levels:

$$
X=X_{0}\left(1-b \exp \left(-a \frac{e}{e_{M}}\right)\right)
$$

where $X_{0}$ is the property of Boom Clay in the far field (intact zone), $\mathrm{X}$ is the property of Boom Clay in the near field (EDZ), $e$ is the global void ratio (see Table 1). In this empirical equation, the damage variable considered is the ratio between $e$ and $e_{M}$.

In Eq. (11), there are two parameters to be determined: $a>0$ is a parameter depending on the material and $b$ is a parameter depending on the property considered $(b>0$ if the property of material decreases with the increase of macro-pores; $b<0$ if the property of material increases with the increase of macropores). Note that the derived fitting parameters $a$ and $b$ have no physical meaning. They just serve to get a good agreement between the laboratory or field values and the modelled values. Thus, this modelling is not based on hydraulic and/or mechanical processes.

\subsection{Determination of parameters}

For Boom Clay, the results of thermal conductivity measurements are used to determine the two parameters $a$ and $b$ by comparing the modelled and experimental results. For this purpose, the values of $\lambda_{\perp}, \lambda_{45}, \lambda_{/ /}$in the far filed $(1.1 \mathrm{~W} /(\mathrm{m} . \mathrm{K}), 1.5 \mathrm{~W} /(\mathrm{m} . \mathrm{K}), 1.65 \mathrm{~W} /(\mathrm{m} . \mathrm{K})$ respectively, see Table 2$)$ are chosen to compute the thermal conductivity at three distance $r=2.5 \mathrm{~m}, 2.7 \mathrm{~m}$ and $9.2 \mathrm{~m}$. With $a=0.05$ and $b=0.5$, a good agreement is obtained between the model prediction and experimental results (Figure 4).

The same model is used to predict the small-strain shear modulus $\left(G_{\mathrm{hv}}, G_{\mathrm{h} 45}, G_{\mathrm{hh}}\right)$ located at three different distances: $r=2.5 \mathrm{~m}, 2.7 \mathrm{~m}$ and $9.2 \mathrm{~m}$. As for the thermal conductivity, the values of $G_{\mathrm{hv}}, G_{\mathrm{h} 45}, G_{\mathrm{hh}}$ in the intact zone and presented in Table 2 are used in the calculations. The predicted results with the same parameters $(a=0.05$ and $b=0.5)$ are compared to that measured in the laboratory in Figure 3 . A good agreement is also obtained. Note that the experimental values of thermal conductivity and smallstrain shear modulus at these three distances $r$ are presented in Table 1.

\subsection{Application of the damage model to the hydraulic property}


In order to verify this damage model for the hydraulic property of natural Boom Clay, the field hydraulic conductivity measurements in 2004 and 2005 (reported by Yu et al., 2011) and those obtained from the same piezometers R55D and R55E in 2012 (taken from the internal report of EURIDICE) are analysed.

322 The results of hydraulic conductivity $k$ measurements in 2004, 2005 and 2012 are presented in Figure 11. 323 Due to the excavation damage in the zone near the gallery, the hydraulic conductivity is quite high in this zone. The extent of EDZ, where the hydraulic conductivity is disturbed, reaches $6 \mathrm{~m}$ from the gallery extrados. Out of the EDZ, the values are about $6.5 .10^{-12} \mathrm{~m} / \mathrm{s}$ for $k_{/ /}$and at $3.5 .10^{-12} \mathrm{~m} / \mathrm{s}$ for $k_{\perp}$ (computed from $k_{\mathrm{g}}$ and $k_{/ /}$using Eq. (1)). Comparison between the results of 2004, 2005 and 2012 shows that the influence of excavation on the hydraulic conductivity in the direction parallel to the bedding plane $\left(k_{/ /}\right)$in 2004 is the same as that in 2005 but larger than that in 2012, which suggests that self-sealing was still in progress from 2005 to 2012. In terms of geometric hydraulic conductivity $k_{\mathrm{g}}$, the results measured in 2004 are almost identical to those obtained in 2005 and 2012.

To apply the proposed damage model to the hydraulic conductivity, parameter $a$ is taken the same as that used for the predictions of thermal conductivity and small strain shear modulus. By contrast, parameter $b$

333 is taken equal to -0.5 because the hydraulic conductivity increases with the increase of macro-pores. All 334 the calculated values $\left(k_{\perp}, k_{/ /}\right)$are then compared to those measured in situ (Figure 11). It is observed that 335 the predicted results are closer to those of the measurements of 2012 as compared with the 336 measurements of 2004 and 2005. This is logic because the values of $e_{\mathrm{M}}$ are determined on samples taken in 2012.

The good agreement obtained between the model prediction and experimental data for the thermal conductivity (Figure 3), small-strain shear modulus (Figure 4) and hydraulic conductivity (Figure 11) shows that the damage variable defined based on the volume of macro-pores is relevant in predicting the effect of EDZ on the thermo-hydro-mechanical properties of natural Boom Clay.

\section{Discussion}

343 Experimental methods aiming at understanding the properties of stiff clay/soft rock in the EDZ often rely 344 on in-situ identification, such as the ultrasonic velocity measurement used for Callovo-Oxfordian claystone 345 (Schuster and Alheid, 2007), Boom Clay (Mertens et al., 2004), and Opalinus Clay (Martin Derek et al., 346 2003), the hydraulic conductivity measurement used for Boom Clay (Yu et al., 2011), Opalinus Clay 347 (Martin Derek et al., 2003), etc. In this study, the measurements of small-strain shear modulus $\left(G_{0}\right)$ and of 348 thermal conductivity $(\lambda)$ were undertaken in the laboratory to quantify the extent of EDZ in Boom Clay. 349 From these measurements, it has been observed that the experimental data of $\lambda$ and $G_{0}$ follows the same 350 evolution law with the distance $r$ from the gallery. -. By contrast, within the EDZ, there is a drastic 351 decrease in its hydro-mechanical performance. This is confirmed by the evolution of hydraulic property 352 reported by Yu et al. (2011): a higher value was obtained in the EDZ as compared to the zone outside the 353 EDZ. The presence of EDZ around Boom Clay formation was also confirmed through the in-situ 354 measurement of compressional wave velocity $\left(V_{P}\right)$ by Mertens et al. (2004). Unfortunately, the boreholes 
used to measure $V_{P}$ in the study of Mertens et al. (2004) are not perpendicular to the connecting gallery, thus the interpretation of data is not straightforward.

357 As for the experimental methods of EDZ identification, the fracture/damage induced by excavation can be identified by mapping excavation surfaces (Lanyon, 2011). Following up this method, a method of tunnel crossing excavation that cut into the side-wall of the previously excavated tunnels was used (Martin and Lanyon, 2004) to detect the extent of EDZ in Opalinus Clay. As for the numerical approaches, there are several methods to predict the extent of EDZ using finite elements, explicit finite difference, distinct element, etc. To simulate the soil damage (fracture growth), a damage variable (usually called $D$ ) is used which is derived from the test results of axial stress and strain, tangential strain, Young's modulus and Poisson's ratio (Hudson, 2009). In this study, the fractures which have the plate and parallel openning form observed at a microscopic scale were considered. Firstly, the global void ratio $(e)$ of the samples taken near and far the gallery was checked to detect the influence of fractures due to excavation on $e_{0}$. Table 1 shows that the values of $e$ of the three samples are almost the same, suggesting that $e_{0}$ is not an indicator of excavation damage. Then, the microstructure investigation of these samples was carried out, allowing the definition of a relevant damage parameter that is the ratio of the global void ratio $\left(e_{0}\right)$ to the void ratio of macro-pores (pore diameter $\geq 5 \mu \mathrm{m})\left(e_{\mathrm{M}}\right)$. When the soil is in the EDZ, there are more macropores, giving rise to larger values of $e_{\mathrm{M}}$. Note that the applicability of this model is related to crack form openings. When the lower damage limit is reached (i.e. undamaged state), the value of $e_{M}$ is very small and $X$ is considered to be equal to $X_{0}$. When the upper damage limit is reached (i.e. totally damaged state), the value of $e_{\mathrm{M}}$ is very high and $e / e_{\mathrm{M}} \approx 0$, hence $X \approx 0$.

As the values of $e_{0}$ for all the three samples are around 0.64 , the damage variable $\left(e / e_{M}\right)$ depend only on $e_{\mathrm{M}}$.

Figure 3, Figure 4, and Figure 11 show some differences between the experimental and prediction results. These differences are due to the chosen values of parameters $a$ and $b$ and the far field values of thermal conductivity, small-strain modulus and hydraulic conductivity (Table 2). In terms of thermal conductivity, the chosen far field values of $\lambda_{/ /}(1.65 \mathrm{~W} /(\mathrm{m} . \mathrm{K}))$ and $\lambda_{45}(1.5 \mathrm{~W} /(\mathrm{m} . \mathrm{K}))$ allow the predictions close to the experimental data. But for $\lambda_{\perp}$, the trend of experimental data is not regular due to the low values measured on the samples of far field: it increases to $1.05 \mathrm{~W} /(\mathrm{m} . \mathrm{K})$ at $r=6.0 \mathrm{~m}$ then decreases to $0.95 \mathrm{~W} /(\mathrm{m} . \mathrm{K})$ at $r=$ $20.8 \mathrm{~m}$. Comparing to the value of $\lambda_{\perp}=1.31 \mathrm{~W} /(\mathrm{m} . \mathrm{K})$ obtained by Chen et al. (2011) by back-analysis, a 384 far field value of $\lambda_{\perp}=1.1 \mathrm{~W} /(\mathrm{m} . \mathrm{K})$ was chosen.

385 In the case of small-strain modulus, the far field values of $G_{\mathrm{hv}}, G_{\mathrm{h} 45}, G_{\mathrm{hh}}$ are more difficult to choose 386 because the measurements by bender element always show some experimental data scatters. Among the 387 three parameters measured $\left(V_{\mathrm{hv}}, V_{\mathrm{hh}}\right.$ and $\left.V_{\mathrm{h} 45}\right)$, it seems that $V_{\mathrm{h} 45}$ is the most difficult to measure. There are several sources that may affect the accuracy of the measurement: identification of the bedding plane, contact between transmitter/receiver and the soil specimen, etc. The final far field values of $G_{\mathrm{hv}}, G_{\mathrm{h} 45}, G_{\mathrm{hh}}$ 390 were chosen after comparing the measurements in this study and the values proposed by Lima (2011) 391 under unconfined conditions. 
In terms of hydraulic conductivity, the in-situ data showed the far field value clearly, but the predicted results under-estimate the values in EDZ, especially in the case parallel to the bedding plane $k_{/ /}$with the measurements conducted in 2004 and 2005 (Figure 11). As mentioned before, this is because parameters $a$ and $b$ are determined based on the measurements on the samples from the borehole drilled in July 2012, with the values of $e_{M}$ that must be lower than those in 2004 and 2005, due to the self-sealing capacity of Boom Clay. The decrease of $e_{M}$ over time is related to the decrease of the dimensions of cracks identified in Figures 8 and 9. The large difference between the predicted results and the data of 2004 and 2005 shows that parameters $a$ and $b$ change over time. In other words, a given set of parameters corresponds to a given time, and the proposed model can be used to estimate the effect of EDZ only for this given time.

\section{Conclusions}

This study aimed at investigating the influence of EDZ around the connecting gallery on the thermal conductivity, small strain modulus and hydraulic conductivity. Several samples of natural Boom Clay at different distances from the gallery were taken from the borecore drilled in July 2012, and thermal conductivity and bender element tests were carried out on these samples. As Boom Clay is a crossanisotropic material, the anisotropy of its properties was investigated by considering different directions with respect to the bedding plane. Microstructural observations were also made using MIP and SEM methods on the samples located at different distances from the gallery. The identified macro-pores were related to the effect of excavation damage, and a damage variable was thus defined, allowing the properties of Boom Clay to be estimated.

413 In terms of thermal measurements, the thermal conductivity $(\lambda)$ in three directions - parallel $\left(\lambda_{/ /}\right)$, 414 perpendicular $\left(\lambda_{\perp}\right)$, and inclined $45^{\circ}\left(\lambda_{45}\right)$ to the bedding plane was measured using the needle probe 415 method. The results showed the same evolution with the distance $r$ from the gallery axis in the three 416 orientations: in the zone far from the gallery, the thermal conductivity stabilises then it drops down to lower 417 values while $r<4 \mathrm{~m}$. An extent of EDZ about $4 \mathrm{~m}$ from the gallery axis (1.6 $\mathrm{m}$ from the gallery extrados) 418 was identified.

419 The mechanical property of Boom Clay around the connecting gallery was investigated through the 420 measurements of the small-strain shear modulus $\left(G_{0}\right)$ by bender element under unconfined conditions. 421 The values in three directions $G_{\mathrm{hv}}, G_{\mathrm{h} 45}, G_{\mathrm{hh}}$ were determined on samples at several distances $r$. Although 422 the experimental results are not as regular as those for the thermal conductivity, an extent of EDZ of about $4234 \mathrm{~m}$ from the gallery axis was also identified.

424 The MIP tests revealed that the samples close to the gallery's wall have macro-pores larger than $5 \mu \mathrm{m}$. 425 These pores correspond to cracks observed at the SEM observations, and can be related to the 426 excavation damage. 
From the void ratio of macro-pore $e_{\mathrm{M}}$ obtained from the MIP tests, a damage variable was defined and a damage model was proposed allowing the prediction of the thermal-hydro-mechanical properties of Boom Clay around the gallery. This model was validated by comparing the predicted and experimental results in terms of thermal conductivity and small-strain shear modulus in different orientations, with the same parameters $a$ and $b$. Further analysis was conducted in terms of hydraulic conductivity. It was observed that satisfactory prediction was obtained for the year 2012 where both the hydraulic conductivity measurement and the sampling for $e_{\mathrm{M}}$ determination were done. The results also suggest that parameters $a$ and $b$ may change over time because of the self-sealing capacity of Boom Clay that leads to a decrease of $e_{M}$ over time.

\section{Acknowledgements}

The authors would like to express their gratitude to Ecole des Ponts ParisTech (ENPC), European Underground Research Infrastructure for Disposal of nuclear waste In Clay Environment (EURIDICE) and Belgian Agency for Radioactive Waste and Enriched Fissile Materials (ONDRAF/NIRAS) for their financial supports.

\section{References}

Ambroziak, A., 2007. Identification and validation of damage parameters for elsto-viscoplastic chaboche model. Eng. Trans. 55, 3-28.

Areias, L., Verstricht, J., Fischer, T., Philipp, J., 2012. Seismic Monitoring at the Underground Nuclear Research Laboratory in MOL, Belgium - 12461, in: WM2012 Conference. Phoenix, Arizona, USA.

Armand, G., Lebon, P., Cruchaudet, M., Rebours, H., Morel, J., Wileveau, Y., Agence, A.-, De, L., Meuse, D., Marne, H., Cedex, C., 2007. EDZ Characterisation in the Meuse / Haute-Marne Underground Research Laboratory, in: Clays in Natural \& Engineered Barriers for Radioactive Waste Confinement. International meeting, September 17-18 2007, Lille, France, pp. 153-154.

Autio, J., Siitari-Kauppib, M., Timonenc, J., Hartikainenc, K., Hartikainenc, J., 1998. Determination of the porosity, permeability and diffusivity of rock in the excavation-disturbed zone around full-scale deposition holes using the View the C14-PMMA and He-gas methods. J. Contam. Hydrol. 35, 19-29.

Bastiaens, W., Bernier, F., Buyens, M., Demarche, M., Li, X.L., Linotte, J.M. and Verstricht, J., 2003. The Connecting Gallery - the extension of the HADES underground research facility at Mol, Belgium. EURIDICE report 03-294. Mol: ESV EURIDICE.

Bernier, F., Li, X.L., Bastiaens, W., Ortiz, L., Van Geet, M., Wouters, L., Frieg, B., Blümling, P., Desrues, J.,Viaggiani, G., Coll, C., Chanchole, S., De Greef, V., Hamza, R., Malinsky, L., Vervoort, A., Vanbrabant, Y., Debecker, B., Verstraelen, J., Govaerts, A., Wevers, M., Labiouse, V., Escoffier, S., Mathier, J.F., Gastaldo, L. and Bühler, Ch., 2006. Fractures and self-healing within the excavation disturbed zone in clays. EC report on the SELFRAC project. 
Bernier, F., Li, X.L., Bastiaens, W., 2007. Twenty-five years' geotechnical observation and testing in the Tertiary Boom Clay formation. Géotechnique 57, 229-237.

Charlier, R., Collin, F., Dizier, A., Fauriel, S., Gens, A., Guangjing, C., Laloui, L., Meynet, T., Pascon, F., Radu, J.P., Marcke, P., Vaunat, J., 2010. Thermal Impact on the Damaged Zone Deliverable D13 Annex 6 Large scale excavation and heater in-situ experiment : the PRACLAY experiment modelling.

Chen, G.J., Sillen, X., Verstricht, J., Li, X.L., 2011. ATLAS III in situ heating test in boom clay: Field data, observation and interpretation. Comput. Geotech. 38, 683-696.

Das, B.M., 1983. Advanced Soil Mechanics. Hemisphere Publishing Corp.

Dehandschutter, B., Vandycke, S., Sintubin, M., Vandenberghe, N., Wouters, L., 2005. Brittle fractures and ductile shear bands in argillaceous sediments: inferences from Oligocene Boom Clay (Belgium). J. Struct. Geol 27, 1095-1112.

Delage, P., Pellerin, F.M., 1984. Influence de la lyophilisation sur la structure d'une argile sensible du Québec. Clays Miner. 19, 151-160.

Delage, P., Le, T.T., Tang, A.M., Cui, Y.J., Li, X.L., 2007. Suction effects in deep Boom Clay block samples. Géotechnique 57, 239-244.

Diamond, S., 1970. Pore size distribution in clays. Clays Clay Min. 18, 7-23.

Farouki, O.T., 1986. Thermal properties of soils. Trans Tech Publications, Clausthal-Zellerfeld, Germany.

Gross, D., Seelig, T., 2011. Damage mechanics, in: Fracture Mechanics SE - 9. Springer Berlin Heidelberg, pp. 301-316.

Hudson, J.A., 2009. Characterising and modelling the excavation damaged zone ( EDZ) in crystalline rock in the context of radioactive waste disposal. Lawrence Berkeley Natl. Lab.

Kachanov, L., 1958. Time of the rupture process under creep conditions. TVZ Akad Nauk S.S.R Otd. Tech. Nauk 8, 26-31.

Lanyon, G.., 2011. Excavation Damaged Zones Assessment, OPG's Deep Geologic Respository for Low \& Intermediate waste. Report of Fracture Systems Ltd - NWMO DGR-TR-2011-21.

Le, T.T., 2008. Comportement thermo-hydro-mécanique de l'argile de Boom. PhD. Ecole Nationale des Ponts et Chaussées.

Lima, A., 2011. Thermo-hydro-mechanical behaviour of two deep Belgian clay formations: Boom and Ypersian Clays. PhD thesis. Universitat Politèchnica de Catalunya.

Martin, C.., Lanyon, G.W., 2004. Excavation Disturbed Zone (EDZ) in Clay Shale: Mont Terri.

Martin Derek, C., Lanyon, G.W., Blümling, P., Mayor, J.., 2003. The excavation disturbed zone around a test tunnel in the Opalinus Clay. Tunn. Assoc. Canada Annu. Publ.

Matray, J.M., Savoye, S., Cabrera, J., 2007. Desaturation and structure relationships around drifts excavated in the well-compacted Tournemire's argillite (Aveyron, France). Eng. Geol. 90, 1-16.

Mertens, J., Bastiaens, W., Dehandschutter, B., 2004. Characterisation of induced discontinuities in the Boom Clay around the underground excavations (URF, Mol, Belgium). Appl. Clay Sci. 26, 413-428. 
Mertens, J., Vandenberghe, N., Wouters, L., Sintubin, M., 2003. The origin and development of joints in the Boom Clay Formation (Rupelian) in Belgium. Geol. Soc. London, Spec. Publ. 216 , 309-321.

Mertens, J., Bastiaens, W., Dehandschutter, B., 2002. Characterisation of induced discontinuities in the Boom Clay around the underground excavations (URF, Mol, Belgium), in: Clays in Natural \& Engineered Barriers for Radioactive Waste Confinement. pp. 43-44.

Nguyen, X.P., 2013. Étude du comportement chimico-hydro- mécanique des argiles raides dans le contexte du stockage de déchets radioactifs. PhD thesis. Université Paris-Est.

Penner, E., 1963. Anisotropic thermal conduction in clay sediments, in: International Clay Conference.

Popp, T., Salzer, K., Minkley, W., 2008. Influence of bedding planes to EDZ-evolution and the coupled HM properties of Opalinus Clay. Phys. Chem. Earth 33, S374-S387.

Romero, E., 1999. Characterisation and thermo-hydro-mechanical behaviour of unsaturated Boom Clay: An experimental study. Universitat Politècnica de Catalunya.

Roy, P., 1991. Measurements of soil permeability anisotropy by three techniques. Thesis. McGill University (Montreal).

Schuster, K., Alheid, H.J., 2007. EDZ characterisation with ultrasonic interval velocity measurements in the URL Meuse/Haute-Marne -performed between depth of $85 \mathrm{~m}$ and $504 \mathrm{~m}$, in: International Meeting "Clay in Natural \& Engineered Barriers for Radioactive Waste Confinement". September 1718, Lille, France, pp. 155-156.

Tang, A.M., Cui, Y.J., Le, T.T., 2008. A study on the thermal conductivity of compacted bentonites. Appl. Clay Sci. $41,181-189$.

Tsang, C.F., Bernier, F., 2004. Definitions of excavation disturbed zone and excavation damaged zone, in Impact of the excavation disturbed or damaged zone (EDZ) on the performance of radioactive waste geological repositories, in: Proceedings European Commission CLUSTER Conference and Workshop on EDZ in Radioactive Waste Geological Repositories. Luxembourg, Belgium.

Tsang, C.F., Bernier, F., Davies, C., 2005. Geohydromechanical processes in the Excavation Damaged Zone in crystalline rock, rock salt, and indurated and plastic clays- in the context of radioactive waste disposal. Int. J. Rock Mech. Min. Sci. 42, 109-125.

Yu, L., Gedeon, M., Wemaere, I., Marivoet, J., De Craen, M., 2011a. Boom Clay Hydraulic Conductivity. A synthesis of 30 years of research. External report SCK-CEN, Mol (Belgium).

Yu, L., Weetjens, E., Vietor, T., 2011b. Integration of TIMODAZ Results within the Safety Case and Recommendations for Repository Design.

Yu, L., Rogiers, B., Gedeon, M., Marivoet, J., Craen, M. De, Mallants, D., 2013. A critical review of laboratory and in-situ hydraulic conductivity measurements for the Boom Clay in Belgium. Appl. Clay Sci. 75-76, 1-12.

Zeng, X., Ni, B., 1999. Stress-Induced anisotropic Gmax of sands and its measurement. J. Geotech. Geoenvironmental Eng. 125, 741-749. 
538 Table 1: Physical and thermo-mechanical properties of natural Boom Clay. $r$ : distance from the axis of 539 gallery, w: water content (\%), $\rho$ : total density of the soil, $\lambda$ : thermal conductivity, $G$ : small-strain shear

540 modulus, e: void ratio; $e_{\mathrm{M}}$ : void ratio of macro-pores.

541 Table 2: Parameters used for model predictions.

542

\section{$543 \quad$ List of Figures}

544 Figure 1: Measurement of thermal conductivity by needle probe method in the laboratory.

545 Figure 2: Measurement of shear wave velocity by bender element method in the laboratory (the three 546 arrows indicate the directions of particle vibration).

547 Figure 3: Comparison of shear modulus between model and experiment.

548 Figure 4: Comparison of thermal conductivity between model and experiment.

549 Figure 5: Bedding plane on natural Boom Clay sample.

550 Figure 6: Pore size distributions of three Boom Clay samples located at different distances from the axis of 551 gallery $r$.

552 Figure 7: Void ratio of macro-pores $e_{M}$ at different distances from the axis of gallery $r$.

553 Figure 8: SEM images viewing perpendicular (a) and parallel (b) to the bedding plane for the sample 554 located at $r=2.5 \mathrm{~m}$; (a) picture scale: $1800 \times 1400 \mu \mathrm{m}$ and (b) picture scale: $1500 \times 1100 \mu \mathrm{m}$.

555 Figure 9: SEM images viewing perpendicular (a) and parallel (b) to the bedding plane for the sample 556 located at $r=2.7 \mathrm{~m}$ : (a) picture scale: $2550 \times 1950 \mu \mathrm{m}$ and (b) picture scale: $850 \times 650 \mu \mathrm{m}$.

557 Figure 10: SEM images viewing perpendicular (a) and parallel to the bedding plane (b) for the sample 558 located at $r=9.2 \mathrm{~m}$ : (a) picture scale: $2300 \times 1800 \mu \mathrm{m}$ and (b) picture scale: $640 \times 500 \mu \mathrm{m}$.

559 Figure 11: Comparison of hydraulic conductivity between the field measurements and model predictions. 560 
Table 1: Physical and thermo-mechanical properties of natural Boom Clay. $r$ : distance from the axis of 563 gallery, w: water content (\%), $\rho$ : total density of the soil, $\lambda$ : thermal conductivity, $G$ : small-strain shear 564 modulus, e: void ratio; $e_{\mathrm{M}}$ : void ratio of macro-pores.

\begin{tabular}{ccccccccccc}
\hline $\begin{array}{c}\text { Distance } \\
\boldsymbol{r}(\mathbf{m})\end{array}$ & $\boldsymbol{w}(\%)$ & $\begin{array}{c}\boldsymbol{\rho} \\
\left(\mathbf{M g} / \mathbf{m}^{3}\right)\end{array}$ & $\boldsymbol{e}$ & $\begin{array}{c}\lambda_{\perp} \\
(\mathbf{W} /(\mathbf{m} . \mathbf{K}))\end{array}$ & $\begin{array}{c}\lambda_{45} \\
(\mathbf{W} /(\mathbf{m} . \mathbf{K}))\end{array}$ & $\begin{array}{c}\lambda_{/ /} \\
(\mathbf{W} /(\mathbf{m} . \mathbf{K}))\end{array}$ & $\begin{array}{c}\mathbf{G}_{\mathrm{hv}} \\
(\mathbf{M P a})\end{array}$ & $\begin{array}{c}\mathbf{G}_{\mathrm{h} 45} \\
(\mathbf{M P a})\end{array}$ & $\begin{array}{c}\mathbf{G}_{\mathrm{hh}} \\
(\mathbf{M P a})\end{array}$ & $\boldsymbol{e} / \mathbf{e}_{\boldsymbol{M}}$ \\
\hline 2.5 & 20.7 & 1.97 & 0.65 & 0.898 & 1.267 & 1.341 & 807.85 & 1065.9 & 819.3 & 12.395 \\
2.7 & 21.3 & 1.97 & 0.64 & 0.818 & 1.230 & 1.421 & 637.55 & 1369.3 & 1197.8 & 26.326 \\
9.2 & 20.3 & 1.95 & 0.64 & 0.941 & 1.477 & 1.605 & 1206.77 & 1357.5 & 1197.8 & 67.107 \\
\hline
\end{tabular}

565

566

567

568

569 Table 2: Parameters used for model predictions.

\begin{tabular}{lr}
\hline \multicolumn{1}{c}{ Property $\boldsymbol{X}$} & \multicolumn{1}{c}{$\boldsymbol{X}_{\mathbf{0}}$} \\
\hline$G_{\mathrm{hv}}(\mathrm{MPa})$ & 1100 \\
$G_{\mathrm{h} 45}(\mathrm{MPa})$ & 1300 \\
$G_{\mathrm{hh}}(\mathrm{MPa})$ & 1450 \\
$V_{\mathrm{P}}(\mathrm{m} / \mathrm{s})$ & 1930 \\
$k_{\perp} \times 10^{-14}(\mathrm{~m} / \mathrm{s})$ & 350 \\
$k_{/ /} \times 10^{-14}(\mathrm{~m} / \mathrm{s})$ & 650 \\
$\lambda_{/ /} \times 10^{-3}(\mathrm{~W} /(\mathrm{m} . \mathrm{K}))$ & 1650 \\
$\lambda_{45} \times 10^{-3}(\mathrm{~W} /(\mathrm{m} . \mathrm{K}))$ & 1500 \\
$\lambda_{\perp} \times 10^{-3}(\mathrm{~W} /(\mathrm{m} . \mathrm{K}))$ & 1100 \\
\hline
\end{tabular}

571

572

573

574

575

576

577

578

579

580 


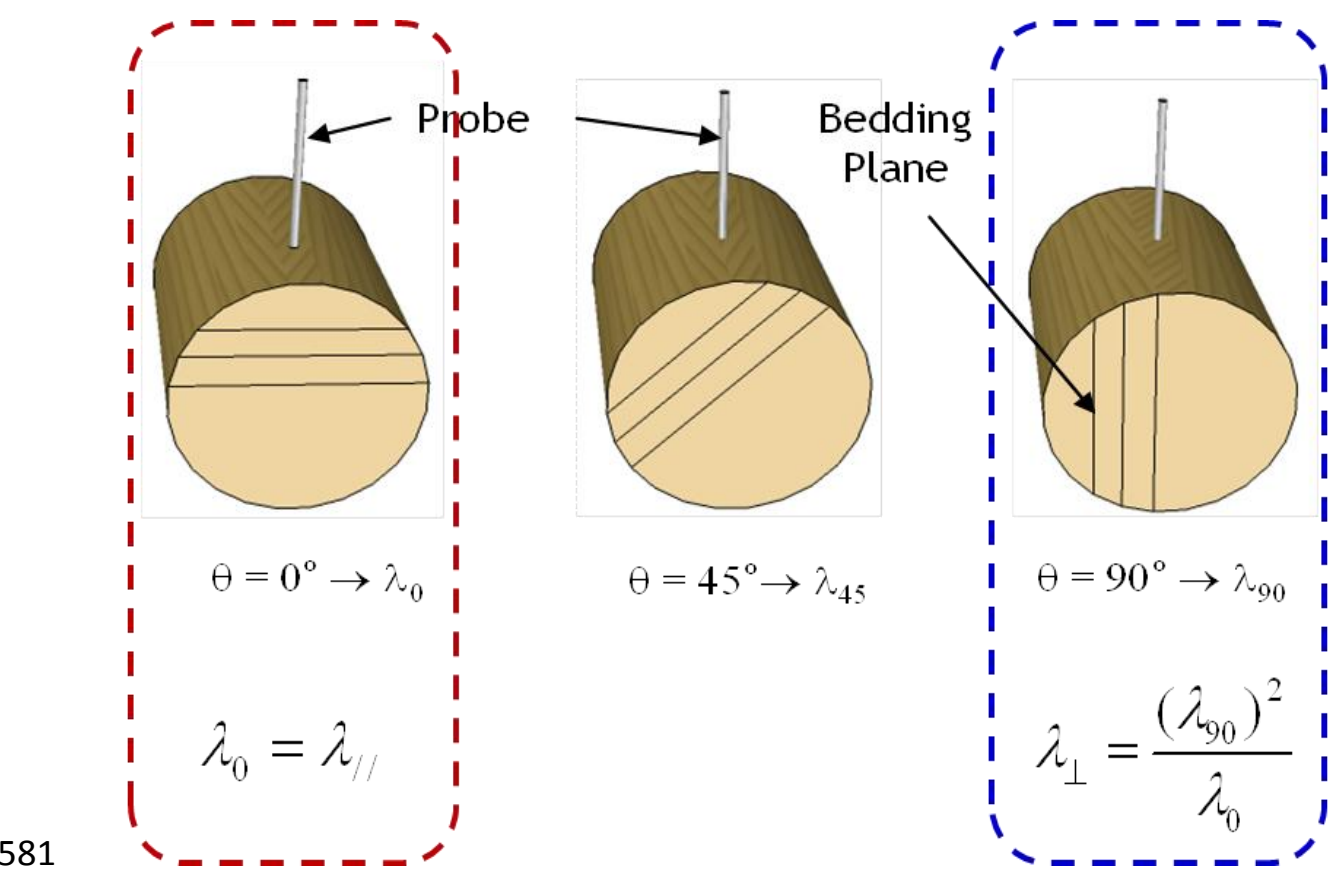

582

583 Figure 1: Measurement of thermal conductivity by needle probe method in the laboratory.

584

585

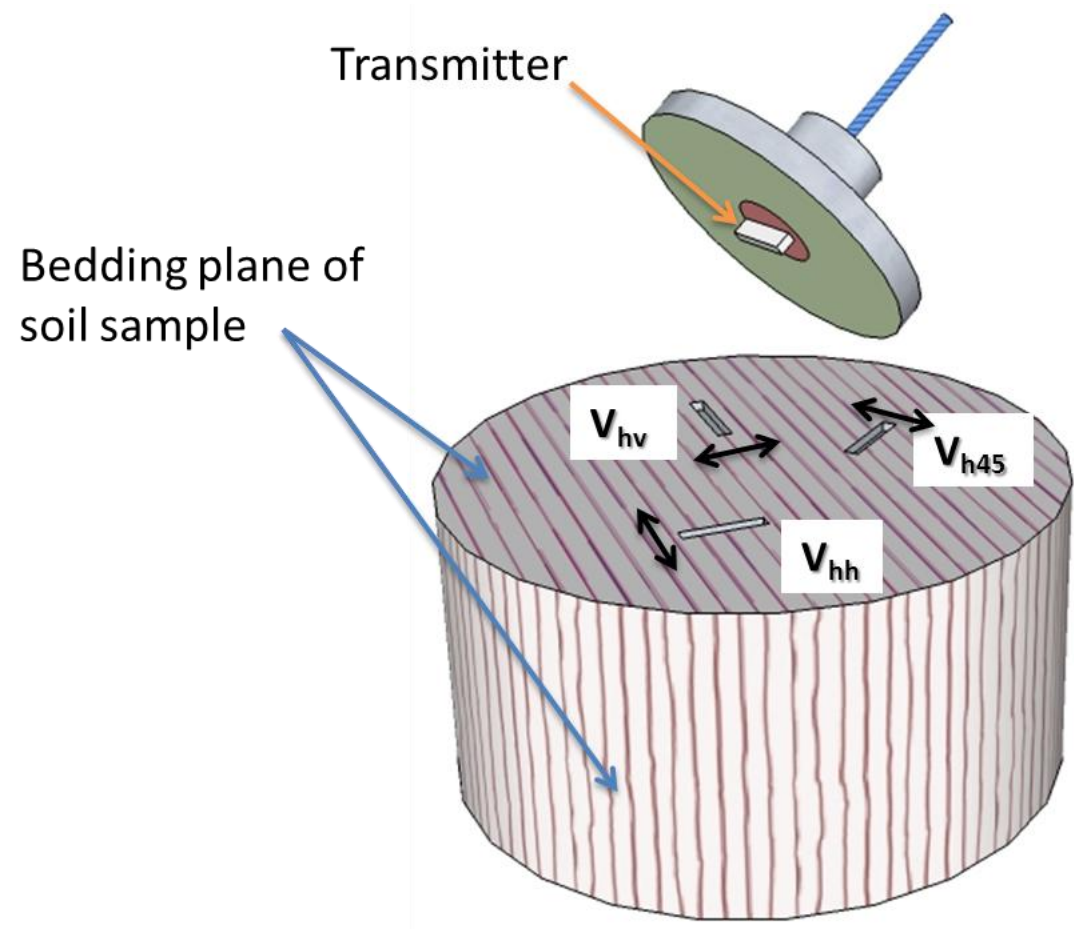

Figure 2: Measurement of shear wave velocity by bender element method in the laboratory (the three 588 arrows indicate the directions of particle vibration). 

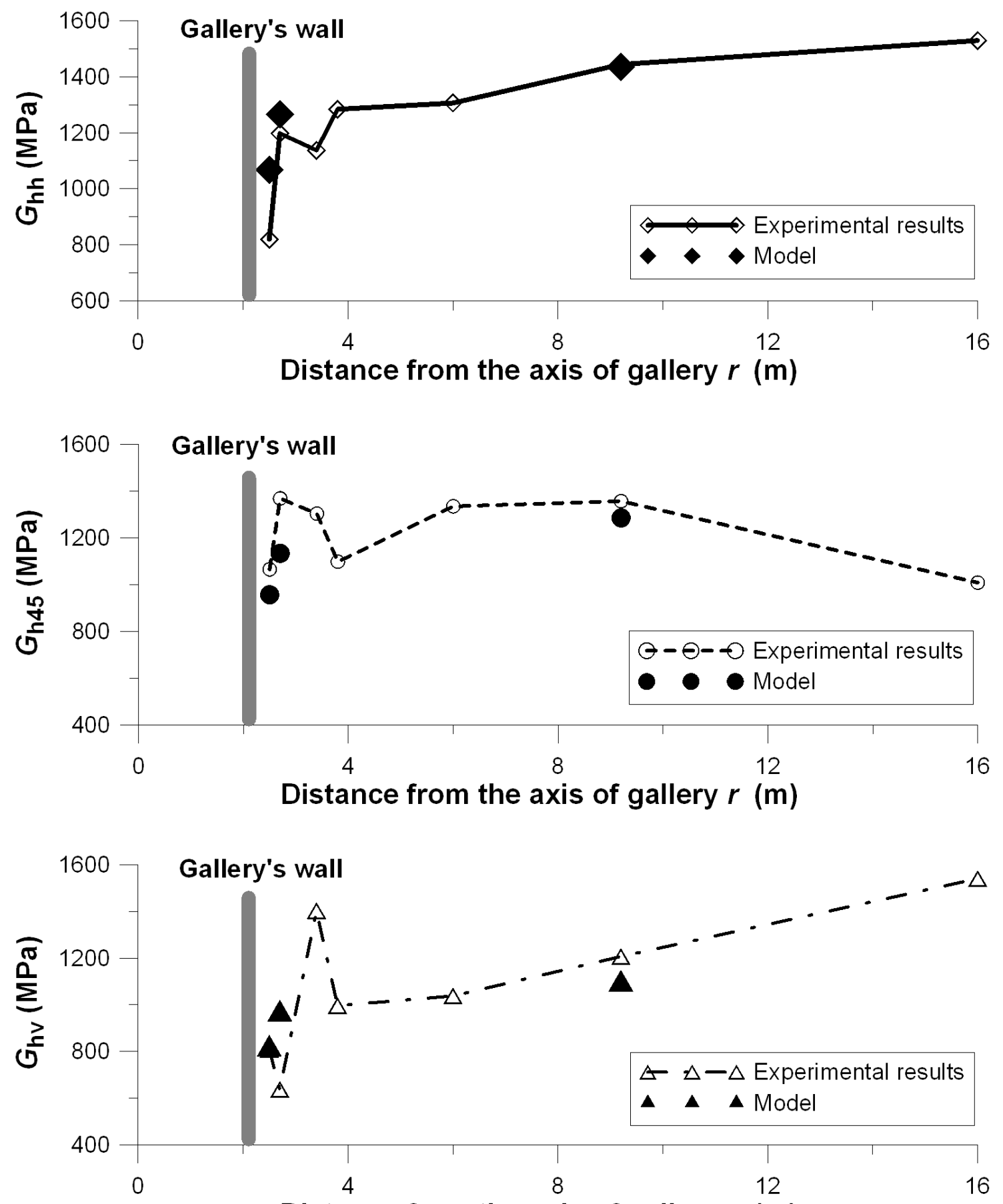

592 Figure 3: Comparison of shear modulus between model and experiment. 

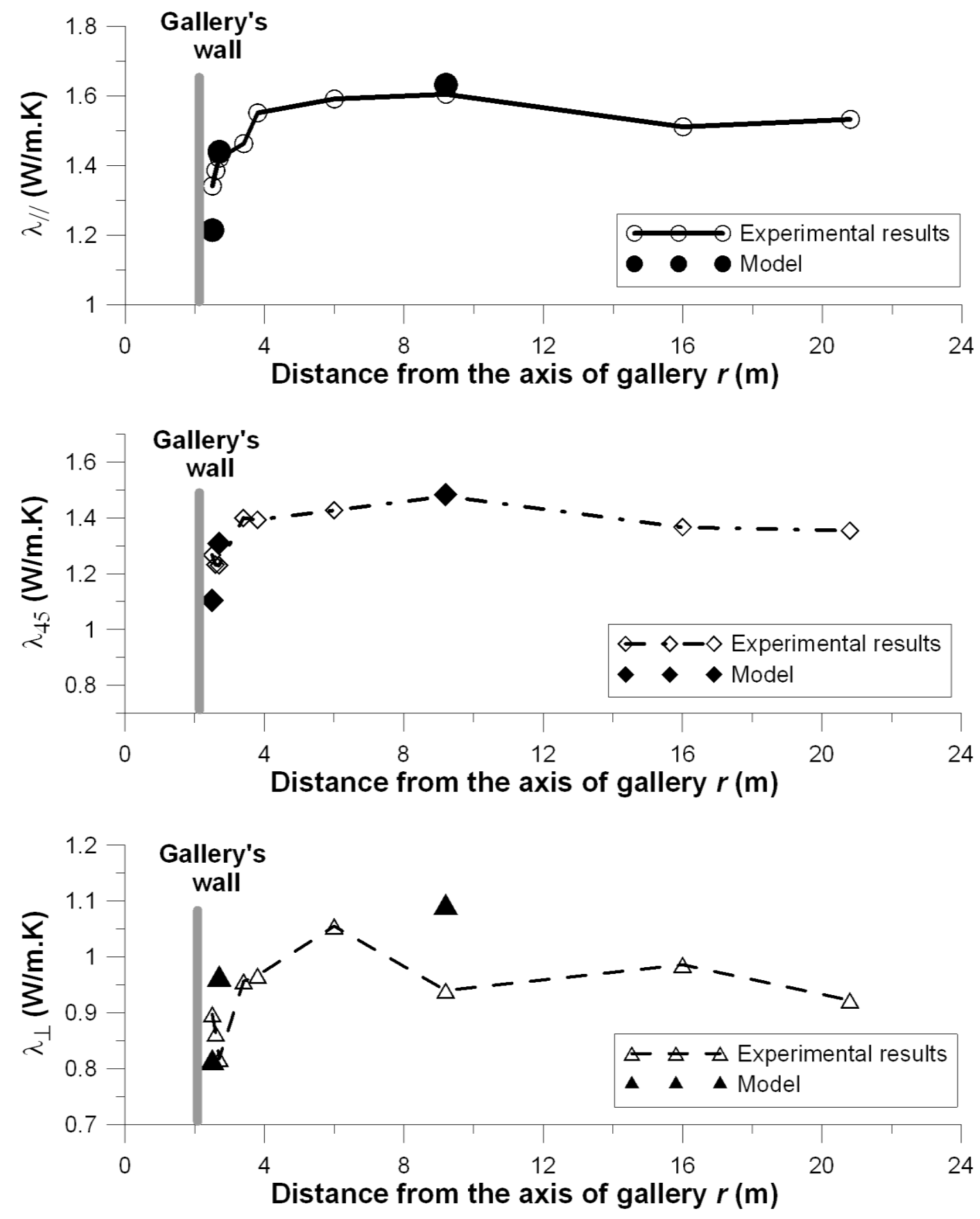

595 Figure 4: Comparison of thermal conductivity between model and experiment. 


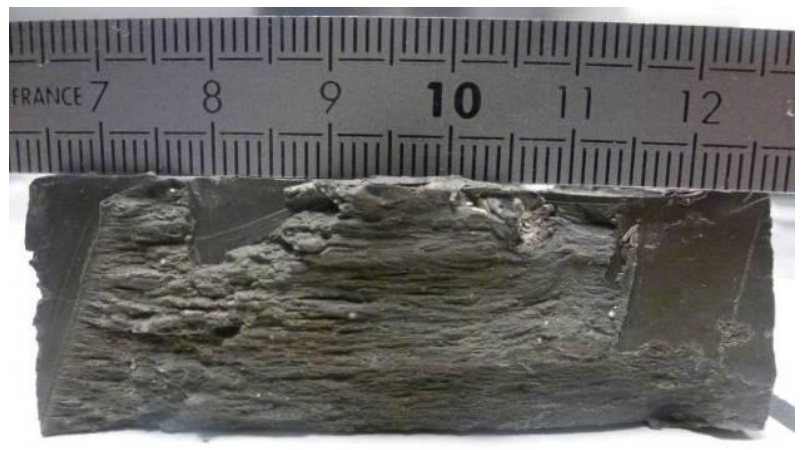

601

602 Figure 5: Bedding plane on natural Boom Clay sample.

603
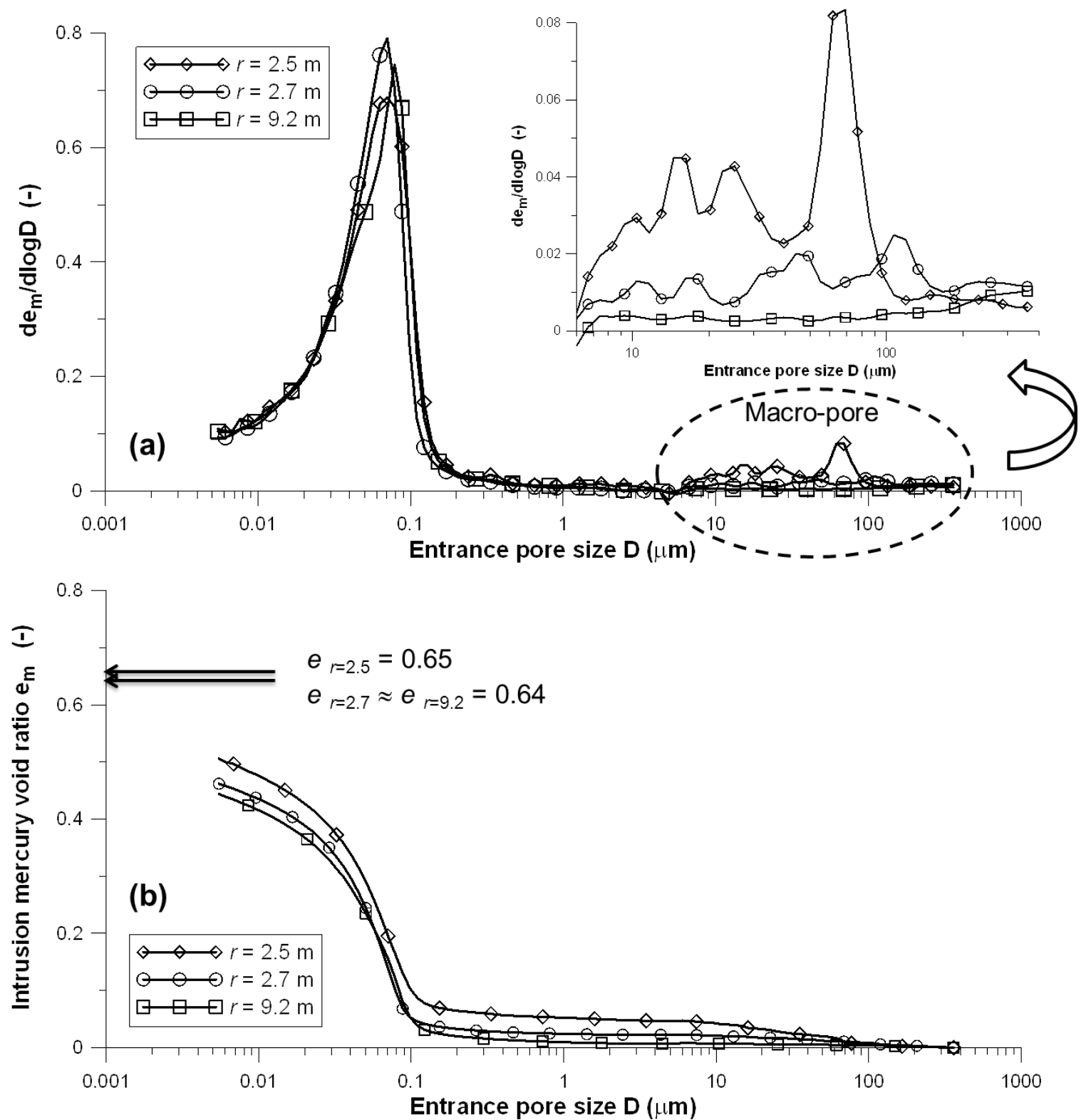

604

Entrance pore size $D(\mu \mathrm{m})$

605 Figure 6: Pore size distributions of three Boom Clay samples located at different distances from the axis of 606 gallery $r$. 


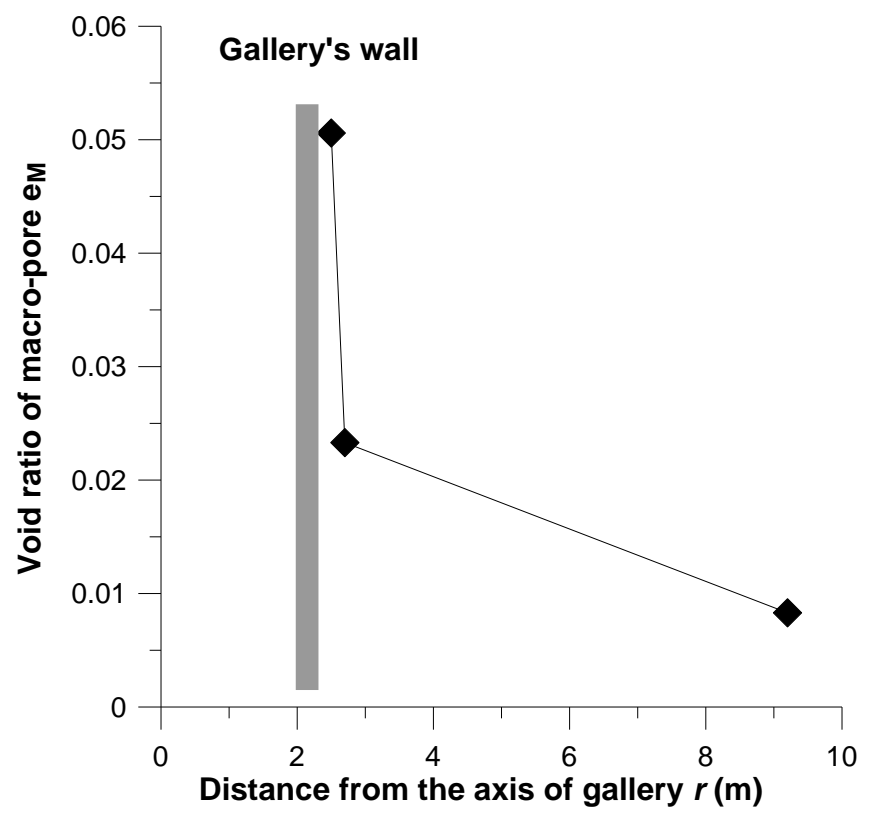

609 Figure 7: Void ratio of macro-pores $e_{\mathrm{M}}$ at different distances from the axis of gallery $r$.
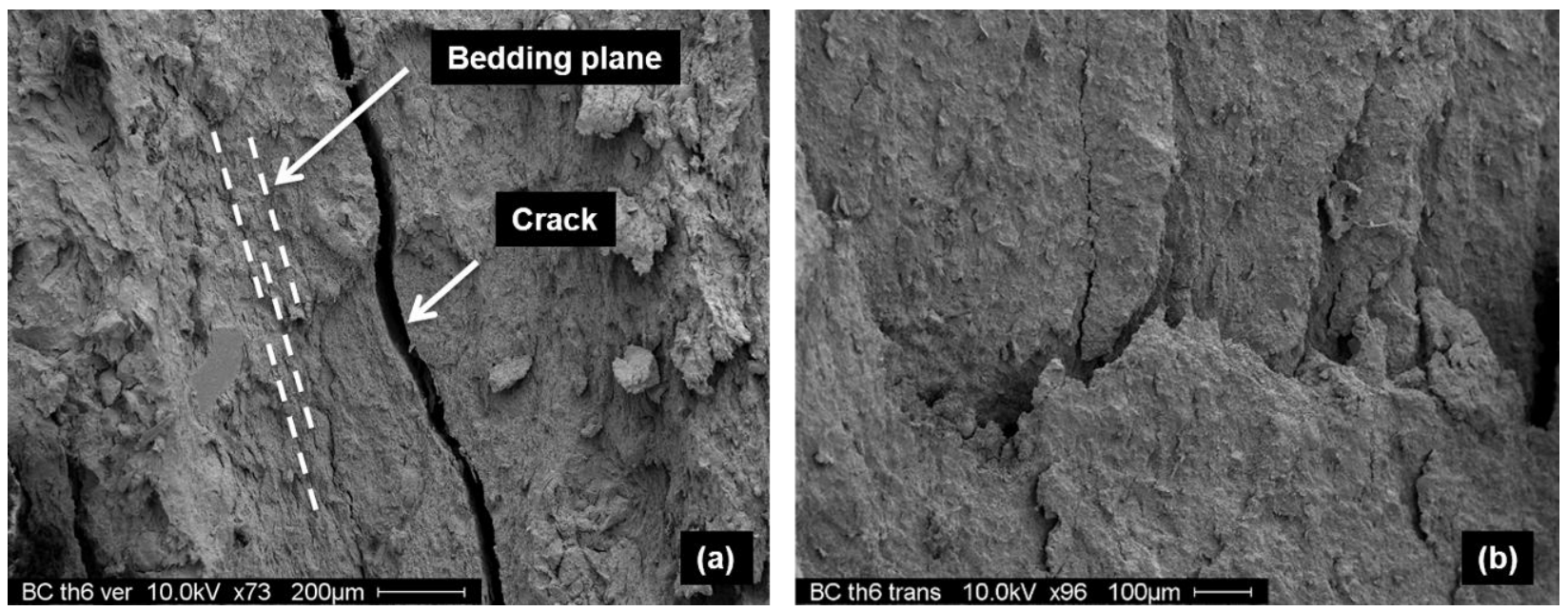

614 Figure 8: SEM images viewing perpendicular (a) and parallel (b) to the bedding plane for the sample 615 located at $r=2.5 \mathrm{~m}$; (a) picture scale: $1800 \times 1400 \mu \mathrm{m}$ and (b) picture scale: $1500 \times 1100 \mu \mathrm{m}$. 

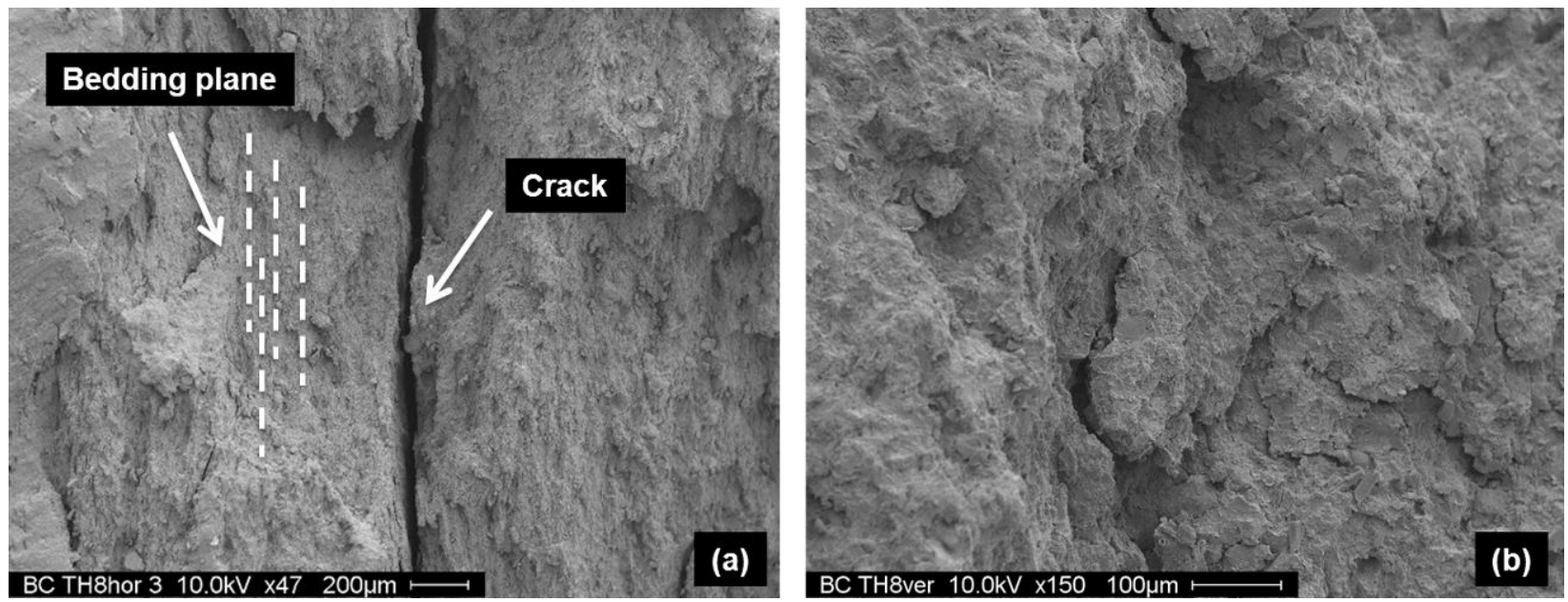

618 Figure 9: SEM images viewing perpendicular (a) and parallel (b) to the bedding plane for the sample 619 located at $r=2.7 \mathrm{~m}$ : (a) picture scale: $2550 \times 1950 \mu \mathrm{m}$ and (b) picture scale: $850 \times 650 \mu \mathrm{m}$.

620
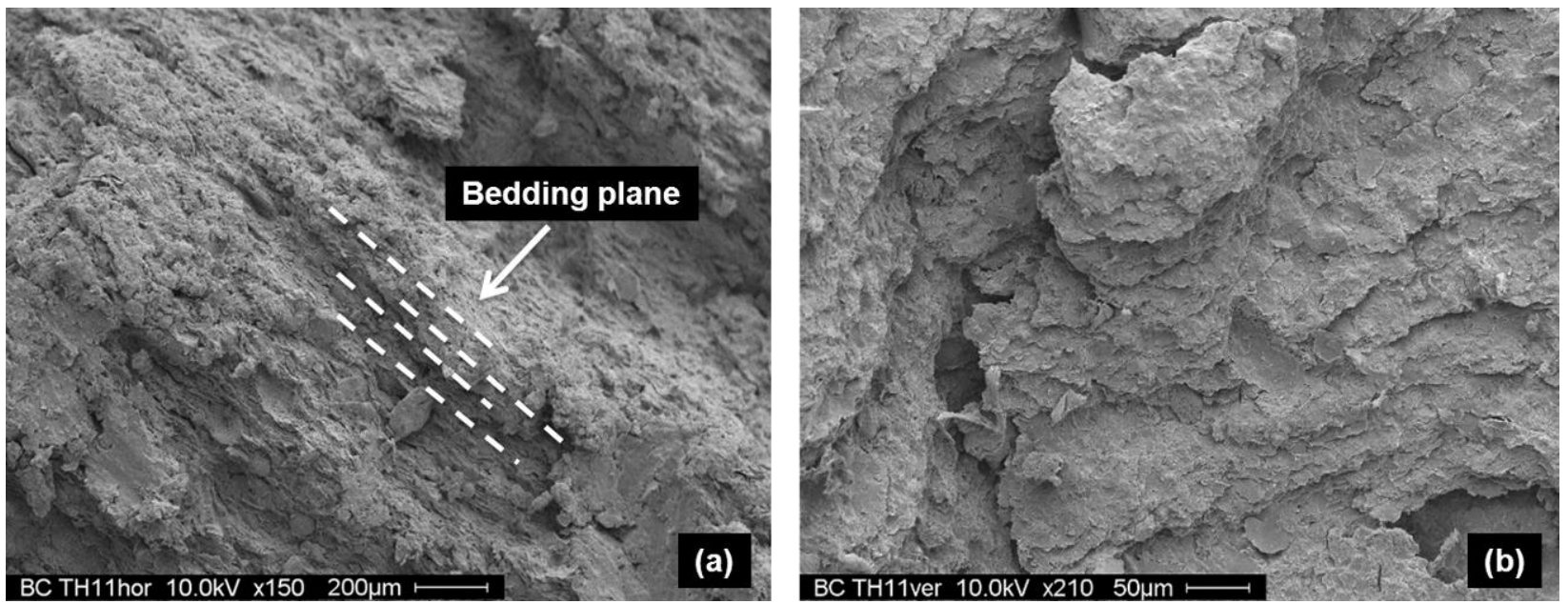

622 Figure 10: SEM images viewing perpendicular (a) and parallel to the bedding plane (b) for the sample 623 located at $r=9.2 \mathrm{~m}$ : (a) picture scale: $2300 \times 1800 \mu \mathrm{m}$ and (b) picture scale: $640 \times 500 \mu \mathrm{m}$. 

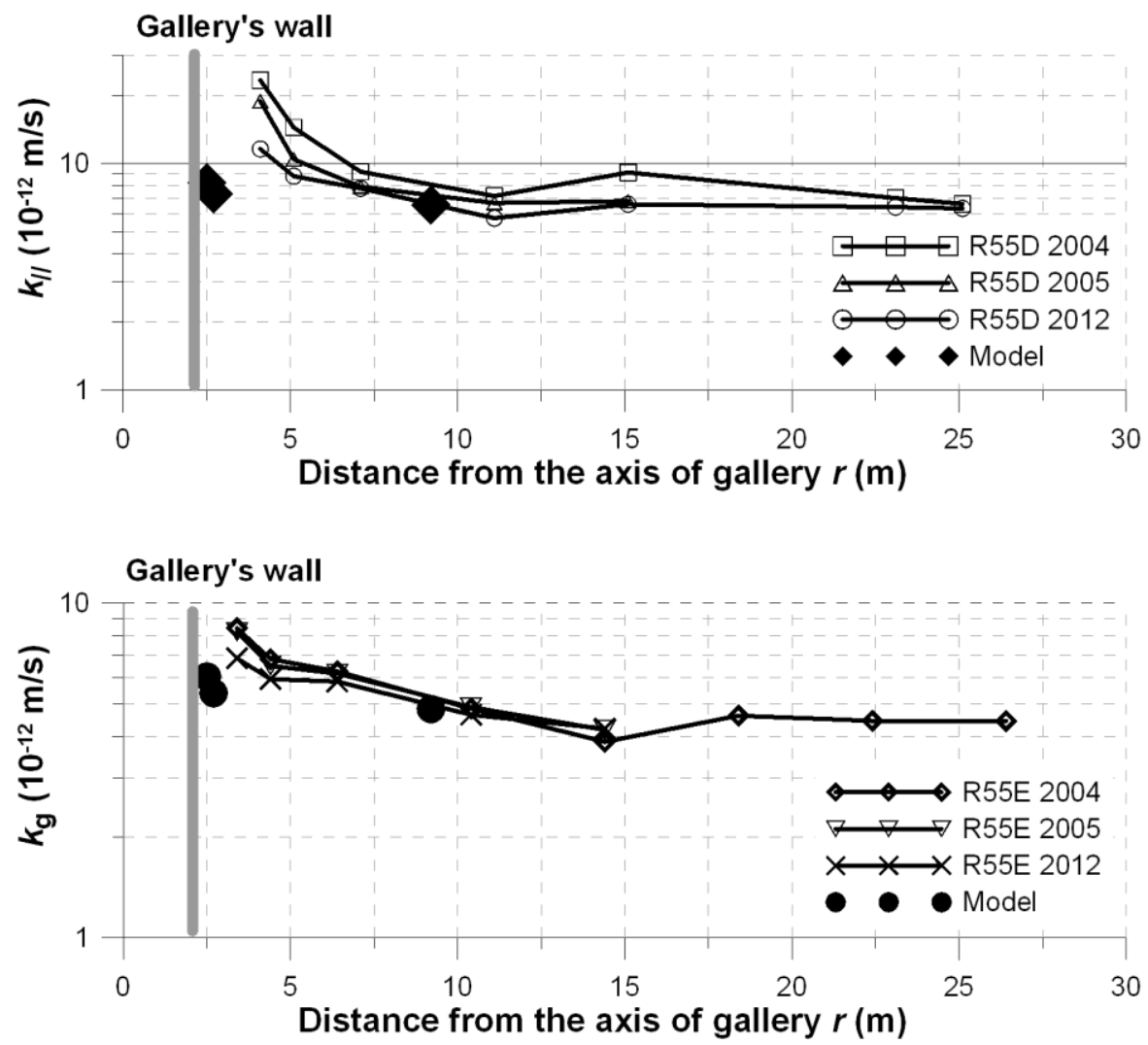

627 Figure 11: Comparison of hydraulic conductivity between the field measurements and model predictions. 